Research Article

\title{
Effectiveness of Punishment and Operating Subsidy in Supervision of China's Pension PPP Projects: An Evolutionary Game and Simulation Analysis
}

\author{
Xianghua Yue $\mathbb{D}^{1}$ and Yuming Lin $\mathbb{D}^{2,3}$ \\ ${ }^{1}$ School of Management, Jinan University, Guangzhou 510632, China \\ ${ }^{2}$ School of Public Administration, Jinan University, Guangzhou 510632, China \\ ${ }^{3}$ Social Security Research Center, Wuhan University, Wuhan 430072, China \\ Correspondence should be addressed to Yuming Lin; linyuming2@sina.com
}

Received 1 July 2019; Revised 30 September 2019; Accepted 4 November 2019; Published 28 November 2019

Academic Editor: Zoran Gajic

Copyright (C) 2019 Xianghua Yue and Yuming Lin. This is an open access article distributed under the Creative Commons Attribution License, which permits unrestricted use, distribution, and reproduction in any medium, provided the original work is properly cited.

\begin{abstract}
Aiming at solving problems of service quality supervision in China's pension PPP projects, this paper mainly analyses the influences of "punishment" and "operating subsidy" on the evolutionary stability strategies of both players through constructing an evolutionary game model between private investors and government regulators. The results show that improving operating subsidy can effectively motivate private investors to improve service quality, and under the active supervision of government regulators, increasing punishment can restrain private investors from violating rules. If government regulators fail to perform their duties, however, punishment will be ineffective to private investors who have broken the rules. Therefore, the Chinese government should take appropriate measures to improve the sense of responsibility of government regulators who appropriately punish private investors providing low-quality services and appropriately increase operating subsidies to private investors offering high-quality services.
\end{abstract}

\section{Introduction}

The public-private-partnership (PPP) is a new mode for the government and private investor to jointly invest in public infrastructure or service projects [1]. In recent years, in order to solve the problem of pension supply and service quality, the promotion and development of pension PPP projects have been highly valued and supported by the Chinese government. At present, more than $90 \%$ of China's pension PPP projects adopt BOT (build-operate-transfer) or BOO (build-own-operate) model. The both modes of operating require high costs from private investors and substantial operating subsidy from the government. In the operating of pension PPP projects, government regulators and private investors may have different objectives and asymmetric information [2], as well as incompleteness and externalities of contracts [3], enabling private investors to take opportunistic actions for pursuing their own interests $[4,5]$. In order to make greater profits, it is possible for private investors to violate the rules and regulations, such as charging high fees but providing low-quality services, setting up consumption traps to cheat, or promising to provide "oldage services" to attract investment. However, at the practical level, because the governments do not participate in the operation of the pension PPP projects, especially because of the lack of service quality supervision system after the implementation of public-private contracts, the operations of these projects are basically in the state of "zero supervision" and "no regulation" [6]. Thus, the service items provided by private investors are of varying quality. These will have a negative impact on the elderly's pension rights, leading to the failure of pension PPP projects.

Sabry believes that good governance and regulatory quality have become important governance variables for promoting private investment and improving government capacity [7]. As a major player in PPP projects, the 
government plays an important role in PPP projects, so good governance is a critical factor in the success of PPP projects [8-10]. Some Chinese scholars who study the supervision of PPP projects believe that the Chinese government should increase the cost of private investors' violations by establishing incentive and punishment mechanisms [11], do a good job of supervision of PPP projects themselves [12], and provide sustained operating subsidies to ensure the healthy and sustainable development of the PPP model [13]. Hence, according to the current situation of PPP project supervision in China and the research results of the above scholars, it is necessary to analyze the impact of such factors as "punishment" and "operating subsidy" on the behavior strategies between private investors and government regulators involved in the operating of pension PPP projects, so as to optimize the supervision mechanism of pension PPP projects. To address the issues, this paper constructs an evolutionary game model between government regulators and private investors based on evolutionary game theory and studies the strategic choice between the two parties in the game process.

Evolutionary game is an evolutionary dynamic process to study group behavior, which contains the idea of replicating dynamics $[14,15]$. It can better represent the dynamic process of group behavior change of individuals, and the evolutionary results can relatively accurately reflect the group behavior of individuals [16]. In the proposed method, government regulators and private investors are considered as game players. In order to choose the best strategy at each stage of the game, government regulators and private investors try to adopt the strategy that they have the highest utility according to that strategy. The game will reach to an evolutionary stability. Therefore, the final solution is calculated according to the best players of each type of strategies at the end of the game.

Evolutionary game theory (EGT) plays an important role in dealing with the mathematics of human intentions [17]. Compared with the classical game theory, evolutionary game holds that the knowledge of game participants is quite limited. Nash's "mass action" is considered to be the earliest theoretical achievement containing more complete evolutionary game theory. According to Nash, it is not necessary to assume that participants have sufficient knowledge of the overall game structure, nor that participants have the desire and ability to make any complex reasoning. It is only necessary to assume that participants can accumulate empirical information about the comparative advantages of various pure strategies when they are adopted, and Nash equilibrium can still be achieved $[18,19]$. The main idea is to find the frequencies of strategies adopted in the population during the evolutionary game process. This feature makes the EGT to be used in various fields, such as social gossip control [20], public goods [21], environmental pollution [22], sustainable tourism [23], coal mine safety [24], and traffic flow and epidemic [25]. There are also some scholars using the EGT to discuss how to regulate PPP projects from different perspectives, mainly in the following two aspects. On one hand, some scholars have explored the importance of punishment in the supervision of PPP projects. Gao et al. constructed an evolutionary game model of new energy PPP projects and concluded that increasing the unit fine could not only promote active cooperating of investors but also reduce government supervision costs [1]. Liu et al. studied the opportunistic behavior of the PPP project during the operating period and discussed the punitive measures imposed by the government [5]. Guo and Li concluded that the penalty for the private sectors' no effort could have an influence on the strategic choice of both government and private sectors by establishing a three-party game model in the old community renovation [26]. Li and $\mathrm{Ma}$ proposed to increase the rent-seeking punishment and reduce the supervision cost by analyzing the evolutionary game behavior between the government and the agent [27]. Gao and Zhao built an evolutionary game model of the government and investors based on new energy power construction PPP projects and concluded that the government can increase unit fines when making dynamic strategic adjustments, which will not only promote the active cooperation of investors but also reduce the probability of government supervision, thereby reducing costs [28]. On the other hand, some scholars have discussed the importance of public participation and reputation in the supervision of PPP projects. Li et al. analyzed the influence of public participation level on public and private behavior based on evolutionary game theory and concluded that the government supervision department will tend to choose supervision strategy with the continuous reduction of supervision cost [29]. Wang et al. constructed a dynamic evolutionary model to analyze the behavior strategies of governments and private investors in the new media era and concluded that the public engagement through new media, government reputation, incentive mechanism, the discovering probability of defaulting behaviors, and the punishment measures are the main factors for the private investors to make decision on the defaulting behaviors [30].

The above literature emphasizes the importance of government regulation and increasing punishment and ignores the role of operating subsidies in the supervision of PPP projects. However, in the early stage of the development of the pension PPP projects in China, is it necessary to increase punishment? Will it be effective to increase punishment? Moreover, the existing literature rarely uses "punishment" and "operating subsidy" as model parameter variables to explore their impact on the choice of behavior strategies of participants in the process of PPP project supervision. Therefore, in order to distinguish it from the research of existing scholars, this paper mainly discusses the validity of factors such as "punishment" and "operating subsidy" in solving the problem of the quality of services provided by private investors which are supervised by government regulators from the mathematical quantitative point of view, mainly with the following characteristics. Firstly, based on the limited rationality of the game players, the supervision of pension PPP service quality is regarded as a dynamic evolution process. The factors such as "punishment" and "operating subsidy" commonly are introduced into the evolutionary game model between government regulators and private investors as variables. The research 
conclusions better reflect the evolutionary equilibrium choices of the behavioral strategies between government regulators and private investors in the supervision of the actual cases, which are more in line with the actual cases of the service quality supervision of pension PPP projects. Secondly, by analyzing the game relationship and strategy adjustment between government regulators and private investors and using Matlab simulation to analyze the evolutionary influence of the evolutionary equilibrium strategies and the impact of key parameter changes on the evolutionary system, it is more intuitive to reflect evolutionary dynamic trends in the process of service quality supervision of pension PPP. Thirdly, based on the conclusions drawn from the analysis, the measures proposed to improve the quality of pension PPP services from the government supervision level are more operational.

The remainder of this paper is organized as follows. Section 2 introduces game relations between government regulators and private investors, model assumptions, and model construction. Section 3 analyzes the evolutionary equilibrium points and the strategies of evolutionary stability between government regulators and private investors. Section 4 is relevant numerical analysis. Section 5 is the conclusions of the paper.

\section{Game Relations and Model Construction}

2.1. Game Relations between Private Investors and Government Regulators. Government departments and private investors form pension PPP project companies according to the explicit contract of public-private contract. According to the Financial (2019) No. 10 document, private investors are responsible for the operating of pension PPP project companies and assume the operating risks of input and output, while government regulators pay strictly according to the performance of project output and bear the risks of policy and law. Private investors get returns through user fees and operating subsidy and pursue maximum profits and shareholder equity. Government regulators establish the service quality standard system and the old-age service guarantee system required by PPP projects in the old-age industry to ensure the maximization of public welfare. However, the government's goal of providing better pension services for the elderly through PPP projects does not depend on whether the government entrusts the operating rights of PPP projects to private investors but on how government regulators regulate private investors. Because of information asymmetry, the contract between the government and private investors cannot be complete. When there are loopholes or failures in government regulation, private investors are prone to opportunistic behavior. Therefore, government regulators need to take effective regulatory measures not only to punish violations but also to link operating subsidy with the quality of service of project operating. In the process of supervision of pension PPP projects, the choice of behavioral strategies of government regulators and private investors interacts with each other, and the evolutionary game of both parties can be regarded as a dynamic game process.
2.2. Parameter Setting and Game Model Construction. Based on the above analysis, the following assumptions between private investors and government regulators are proposed.

Assumption 1. Private investors and government regulators are considered as game players. Under the condition of information asymmetry, the game players are both with bounded rationality, and each of them does not have a full understanding about their opponent's strategy and benefit function. They will continuously adjust their strategy during the game until the optimal strategy is found.

Assumption 2. Private investors' strategy space is defined as $I=(\mathrm{HQ}, \mathrm{LQ})$. HQ (providing high-quality services) represents that private investors compliance with publicprivate contracts and government regulation quality standards to improve the quality of aged care services, where the cost is $C_{\mathrm{H}}$. LQ (providing low-quality services) represents that private investors violate public-private contracts and government regulatory quality standards in order to make more profits by reducing the quality of pension services, where the cost is $C_{\mathrm{L}}$, and at this time, $C_{\mathrm{H}}>C_{\mathrm{L}} \cdot V_{\mathrm{s}}$ refers to the income from the sale of pension services by private investors. $R_{\mathrm{e}}$ refers to the government's operating subsidy income to private investors for HQ. $F_{s}$ refers to the fines imposed by government regulators on private investors for $\mathrm{LQ}$.

Assumption 3. Government regulators' strategy space is defined as $R=$ (AS, NS). AS (active supervision) indicates that government regulators actively supervise the operating and service quality of PPP projects for the aged in order to avoid private investor violations, where the income available is $R_{g}$ and the required cost is $C_{\mathrm{g}}$. NS (negative supervision) indicates that government regulators do not punish private investors with low-quality services, where the income available and the required cost are both 0 . However, in this case, due to the failure to find the quality of service in time, government regulators will be subject to public complaints and punishment by higher authorities, and the loss will be $F_{\mathrm{g}}$.

Assumption 4. $x(0 \leq x \leq 1)$ is the probability that private investors adopt HQ strategy, and then $1-x$ means the probability that manufacturers adopt LQ strategy. $y(0 \leq y \leq 1)$ is the probability that government regulators adopt AS strategy, and then $1-y$ represents the probability that government regulators adopt NS strategy.

In order to simplify the model, it is assumed that if government regulators carry out the supervision work actively, it will absolutely discover and deal with the problem of LQ, and if government regulators conducted negatively, the problem of LQ will not be investigated or solved. According to the above assumptions, the payoff matrix of private investors and government regulators is shown in Table 1. 
TABle 1: Payoff matrix of private investors and government regulators.

\begin{tabular}{lcc}
\hline \multirow{2}{*}{ Private investors } & \multicolumn{2}{c}{ Government regulators } \\
& $\mathrm{AS}(y)$ & $\mathrm{NS}(1-y)$ \\
\hline HQ $(x)$ & $V_{\mathrm{s}}+R_{\mathrm{e}}-C_{\mathrm{H}}, R_{\mathrm{g}}-C_{\mathrm{g}}$ & $V_{\mathrm{s}}+R_{\mathrm{e}}-C_{\mathrm{H}}, 0$ \\
LQ $(1-x)$ & $V_{\mathrm{s}}-C_{\mathrm{L}}-F_{\mathrm{s}}, R_{\mathrm{g}}-C_{\mathrm{g}}$ & $V_{\mathrm{s}}-C_{\mathrm{L}},-F_{\mathrm{g}}$ \\
\hline
\end{tabular}

\section{Evolutionary Game Analysis}

3.1. Equilibrium Point of Evolutionary Process. According to the evolutionary game payment matrix above, the expected returns of private investors in choosing the strategies of HQ and LQ and the average expected returns of private investors are obtained, respectively:

$$
\begin{aligned}
Y_{11}= & y\left(V_{\mathrm{s}}+R_{\mathrm{e}}-C_{\mathrm{H}}\right)+(1-y)\left(V_{\mathrm{s}}+R_{\mathrm{e}}-C_{\mathrm{H}}\right) \\
= & V_{\mathrm{s}}+R_{\mathrm{e}}-C_{\mathrm{H}}, \\
Y_{12}= & y\left(V_{\mathrm{s}}-C_{\mathrm{L}}-F_{\mathrm{s}}\right)+(1-y)\left(V_{\mathrm{s}}-C_{\mathrm{L}}\right) \\
= & -y F_{\mathrm{s}}+V_{\mathrm{s}}-C_{\mathrm{L}}, \\
\bar{Y}_{1}= & x Y_{11}+(1-x) Y_{12}=x\left(V_{\mathrm{s}}+R_{\mathrm{e}}-C_{\mathrm{H}}\right) \\
& +(1-x)\left[-y F_{\mathrm{s}}+\left(V_{\mathrm{s}}-C_{\mathrm{L}}\right)\right] .
\end{aligned}
$$

According to the Malthusian dynamic equation [31], the growth rate of the number of HQ is equal to $Y_{11}-\bar{Y}_{1}$ and $t$ is regarded as the time, so private investors' replication dynamic equation can be obtained as

$$
J=\left[\begin{array}{c}
(1-2 x)\left(y F_{\mathrm{s}}+R_{\mathrm{e}}-C_{\mathrm{H}}+C_{\mathrm{L}}\right) \\
-y(1-y) F_{\mathrm{g}}
\end{array}\right.
$$

If the following two conditions are met at the same time, the equilibrium point of the replication dynamic equation will be the evolutionary stability strategy (ESS).

(1) $\operatorname{tr} J=(1-2 x)\left(y F_{\mathrm{s}}+R_{\mathrm{e}}-C_{\mathrm{H}}+C_{\mathrm{L}}\right)+(1-2 y)[(1-$ $\left.x) F_{\mathrm{g}}+R_{\mathrm{g}}-C_{\mathrm{g}}\right]<0$ (condition of the trace)

(2) $\operatorname{det} J=(1-2 x)\left(y F_{\mathrm{s}}+R_{\mathrm{e}}-C_{\mathrm{H}}+C_{\mathrm{L}}\right)(1-2 y)[(1-$ $\left.x) F_{\mathrm{g}}+R_{\mathrm{g}}-C_{\mathrm{g}}\right]-x(1-x) F_{\mathrm{s}}(1-2 y)\left[(1-x) F_{\mathrm{g}}+\right.$ $\left.R_{\mathrm{g}}-C_{\mathrm{g}}\right]>0$ (condition of the Jacobi determinant)

Since there is $\operatorname{tr} J=0$ at the local equilibrium point $\left(x^{*}, y^{*}\right)$, it is not the equilibrium point of the system evolution stability strategy. Therefore, only $\operatorname{tr} J$ and $\operatorname{det} J$ of the Jacobian matrix at the remaining four local equilibrium points need to be considered, and the stability of the system $L$ needs to be analyzed from five cases as follows. Local stability analysis of case 1 and case 2 is shown in Table 2, and the judgment methods of other cases are the same, which will not be listed here one by one.

Case 1. When $R_{\mathrm{e}}<C_{\mathrm{H}}-C_{\mathrm{L}}<F_{\mathrm{s}}+R_{\mathrm{e}}$ and $R_{\mathrm{g}}<C_{\mathrm{g}}-F_{\mathrm{g}}$ at the same time or when $F_{\mathrm{s}}+R_{\mathrm{e}}<C_{\mathrm{H}}-C_{\mathrm{L}}$ and $R_{\mathrm{g}}<C_{\mathrm{g}}-F_{\mathrm{g}}$ at the same time, the evolutionary stability strategy (ESS) of system $L$ is $(0,0)$. $\left.\begin{array}{c}x(1-x) F_{\mathrm{s}} \\ (1-2 y)\left[(1-x) F_{\mathrm{g}}+R_{\mathrm{g}}-C_{\mathrm{g}}\right]\end{array}\right]$.

$$
Y(x)=\frac{\mathrm{d} x}{\mathrm{~d} t}=x\left(Y_{11}-\bar{Y}_{1}\right)=x\left((1-x)\left(y F_{\mathrm{s}}+R_{\mathrm{e}}-C_{\mathrm{H}}+C_{\mathrm{L}}\right) .\right.
$$

In the same way, the government regulators' replication dynamic equation can be obtained as

$$
G(y)=\frac{\mathrm{d} y}{\mathrm{~d} t}=y(1-y)\left[(1-x) F_{\mathrm{g}}+R_{\mathrm{g}}-C_{\mathrm{g}}\right] .
$$

According to the above analysis, a two-dimensional power system $L$ can be obtained from the formulas (2) and (3), that is:

$$
\left\{\begin{array}{l}
\frac{\mathrm{d} x}{\mathrm{~d} t}=x(1-x)\left(y F_{\mathrm{s}}+R_{\mathrm{e}}-C_{\mathrm{H}}+C_{\mathrm{L}}\right), \\
\frac{\mathrm{d} y}{\mathrm{~d} t}=y(1-y)\left[(1-x) F_{\mathrm{g}}+R_{\mathrm{g}}-C_{\mathrm{g}} .\right.
\end{array}\right.
$$

Let $\mathrm{d} x / \mathrm{d} t=0$ and $\mathrm{d} y / \mathrm{d} t=0$, then we can know that $(0,0),(0,1),(1,0),(1,1)$, and $\left(x^{*}, y^{*}\right)$ are the equilibrium points of the system. Among them, $x^{*}=\left(F_{\mathrm{g}}+R_{\mathrm{g}}-C_{\mathrm{g}}\right) / F_{\mathrm{g}}$ and $y^{*}=\left(C_{\mathrm{H}}-C_{\mathrm{L}}-R_{\mathrm{e}}\right) / F_{\mathrm{s}}$ and $y^{*}=\left(C_{\mathrm{H}}-C_{\mathrm{L}}-R_{\mathrm{e}}\right) / F_{\mathrm{s}}$.

3.2. Stability Analysis of Equilibrium Points and Evolutionary Strategies. According to the literature [32], the Jacobian matrix $J$ of the two-dimensional dynamic system $L$ is

Case 2. When $R_{\mathrm{e}}<C_{\mathrm{H}}-C_{\mathrm{L}}<F_{\mathrm{s}}+R_{\mathrm{e}}$ and $C_{\mathrm{g}}-F_{\mathrm{g}}<R_{\mathrm{g}}<C_{\mathrm{g}}$ at the same time, there is no evolutionary stability strategy (ESS) in system $L$.

Case 3. When $R_{\mathrm{e}}>C_{\mathrm{H}}-C_{\mathrm{L}}$ and $R_{\mathrm{g}}<C_{\mathrm{g}}$ at the same time, the evolutionary stability strategy (ESS) of system $L$ is $(1,0)$.

Case 4. When $F_{\mathrm{s}}+R_{\mathrm{e}}<C_{\mathrm{H}}-C_{\mathrm{L}}$ and $C_{\mathrm{g}}-F_{\mathrm{g}}<R_{\mathrm{g}}<C_{\mathrm{g}}$ at the same time or when $F_{\mathrm{s}}+R_{\mathrm{e}}<C_{\mathrm{H}}-C_{\mathrm{L}}$ and $R_{\mathrm{g}}>C_{\mathrm{g}}$ at the same time, the evolutionary stability strategy (ESS) of system $L$ is $(0,1)$.

Case 5. When $R_{\mathrm{e}}>C_{\mathrm{H}}-C_{\mathrm{L}}$ and $R_{\mathrm{g}}>C_{\mathrm{g}}$ at the same time or when $R_{\mathrm{e}}<C_{\mathrm{H}}-C_{\mathrm{L}}<R_{\mathrm{e}}+F_{\mathrm{s}}$ and $R_{\mathrm{g}}>\mathscr{C}_{\mathrm{g}}$ at the same time, the evolutionary stability strategy (ESS) of system $L$ is $(1,1)$.

\section{Numerical Analysis}

Based on the analysis of evolutionary stability of both sides of the game under the above different conditions, we take the PPP projects of pension institution in China's pension industry as examples, assign values to each parameter, perform numerical evolution and simulation analysis, and then use 
TABLe 2: Local stability analysis of case 1 and case 2 .

\begin{tabular}{|c|c|c|c|c|c|c|c|c|c|}
\hline \multicolumn{7}{|c|}{ Case 1} & \multicolumn{3}{|c|}{ Case 2} \\
\hline & \multicolumn{3}{|c|}{$R_{\mathrm{e}}<C_{\mathrm{H}}-C_{\mathrm{L}}<F_{\mathrm{s}}+R_{\mathrm{e}}$ and } & \multicolumn{3}{|c|}{$F_{\mathrm{s}}+R_{\mathrm{e}}<C_{\mathrm{H}}-C_{\mathrm{L}}$ and $R_{\mathrm{g}}<C_{\mathrm{g}}-F_{\mathrm{g}}$} & \multicolumn{3}{|c|}{$\begin{array}{c}R_{\mathrm{e}}<C_{\mathrm{H}}-C_{\mathrm{L}}<F_{\mathrm{s}}+R_{\mathrm{e}} \text { and } \\
C-F<R<C\end{array}$} \\
\hline Balance point & $\operatorname{tr} J$ & $\operatorname{det} J$ & Local stability & $\operatorname{tr} J$ & $\operatorname{det} J$ & Local stability & $\operatorname{tr} J$ & $\operatorname{det} J$ & Local stability \\
\hline$(0,0)$ & - & + & ESS & - & + & ESS & \pm & - & Saddle point \\
\hline$(1,0)$ & \pm & - & Saddle point & \pm & - & Saddle point & \pm & - & Saddle point \\
\hline$(0,1)$ & \pm & - & Saddle point & + & + & Instability point & \pm & - & Saddle point \\
\hline$(1,1)$ & + & + & Instability point & \pm & - & Saddle point & \pm & - & Saddle point \\
\hline
\end{tabular}

Matlab software to simulate the dynamics evolution process of strategic selection between government regulators and private investors. In order to make the simulation results more scientific and objective, it is assumed that there are 100 beds in PPP project center of an old-age institution which collect the elderly with good evaluation ability by means of market payment. According to the actual situation of our country, the following parameters have been rationally allocated, but it cannot fully represent the actual situation in the process of supervision of the pension PPP project. For example, China's provincial civil affairs departments provide an operating subsidy of 2400-4800 RMB per year for an elderly person with good assessment ability in pension institutions. We assign a median value of 3600 RMB per year to $R_{\mathrm{e}}$. The initial assignment of each parameter under the above evolutionary stabilization strategy is shown in Table 3 (unit: million RMB per year).

4.1. Verification of Evolutionary Stability Strategy Case. Suppose the horizontal axis represents the probability of private investors providing high-quality services, and the vertical axis represents the probability of active supervision by government regulators. The five different initial ratios $x=0.1, y=0.1, x=0.2, y=0.2, x=0.4, y=0.4$, $x=0.7, y=0.7$, and $x=0.9, y=0.9$ are randomly assigned to each game player in the game. The simulation is shown in Figures 1-6.

(1) Figure 1 shows that the system eventually tends to be in the stable state of $(0,0)$.That is to say, under different initial ratios of $x$ and $y$, private investors initially have a large proportion of the HQ strategies. But, when operating subsidy obtained by private investors by HQ are less than the cost saved by LQ and when the government's penalties for private investors by LQ are lighter, making the net benefit of choosing the HQ strategy less than the net benefit of choosing the LQ strategy, private investors tend to choose the strategy of HQ than to choose the strategy of LQ. Similarly, many government regulators initially choose the strategy of AS in order to maximize social interests. But, when the cost of AS is higher than the supervision income and when the punishment of dereliction of duty by higher government is lighter, making the net income choosing the AS strategy less than the net income of choosing the NS strategy, government regulators have changed their choice of the AS strategy to the NS strategy. The interaction between the two sides evolved to the worst equilibrium point. At this time, the government regulatory mechanism is in an "ineffective" state, the service quality guarantee level of the pension PPP market is the lowest, and the overall social utility is the smallest. If this "invalid" state continues, it will lead to the failure of the pension PPP projects.

(2) Figure 2 shows that the system does not have a unique evolutionary stable point. That is to say, under different initial ratios, when the cost saved by LQ of private investors is higher than the operating subsidy obtained by HQ and is lower than the sum of the punishment for violations and the operating subsidy for HQ at the same time, and when government regulators' profits are greater than the difference between supervision costs and punishment for dereliction of duty and are lower than the supervision costs at the same time, the evolution trends of the interaction behavior of private investors and government regulators are similar, and they are all in a cyclical state with no stable evolution strategy. This is in line with the fact that most of government regulators in China usually adopt an active regulation during the high-incidence season of old-age service and adopt a negative intermittent supervision mode during the low-incidence period. At this time, the government's supervision mechanism can only temporarily curb the service quality of pension PPP projects, but it cannot promote private investors to improve the service quality for the aged for a long time and thoroughly solve the problem of the service quality for the aged.

(3) Figure 3 shows that the system eventually tends to be in the stable state of $(1,0)$. That is to say, when the operating subsidy obtained by private investors by HQ is greater than the cost saved by LQ and when the profits gained by the active regulation of government regulators are less than the regulatory costs, the system will eventually evolve into a negative "locked" state in which private investors adopt HQ strategy and government regulators choose to trust private investors, thus choosing NS strategy. The interaction between the two sides has evolved to a subinferior equilibrium. At this time, the government supervision mechanism is in a bad "lock-in" state. Long-term NS by government regulators may lead to high operating subsidy for pension PPP 
TABLE 3: Simulated values of parameters in the case of evolutionary stabilization strategy.

\begin{tabular}{cccccccccc}
\hline & Evolutionary stability and conditions & $C_{\mathrm{H}}$ & $C_{\mathrm{L}}$ & $R_{\mathrm{e}}$ & $F_{\mathrm{s}}$ & $F_{\mathrm{g}}$ & $R_{\mathrm{g}}$ & $C_{\mathrm{g}}$ & Simulation diagram \\
\hline \multirow{2}{*}{ Case 1} & $R_{\mathrm{e}}<C_{\mathrm{H}}-C_{\mathrm{L}}<F_{\mathrm{s}}+R_{\mathrm{e}}$ and $R_{\mathrm{g}}<C_{\mathrm{g}}-F_{\mathrm{g}}$ & 4.8 & 4.2 & 0.36 & 0.5 & 0.3 & 0.2 & 0.6 & Figure 1(a) \\
Case 2 & $F_{\mathrm{s}}+R_{\mathrm{e}}<C_{\mathrm{H}}-C_{\mathrm{L}}$ and $R_{\mathrm{g}}<C_{\mathrm{g}}-F_{\mathrm{g}}$ & 4.8 & 4.2 & 0.36 & 0.1 & 0.3 & 0.2 & 0.6 & Figure 1(b) \\
Case 3 & $R_{\mathrm{e}}<C_{\mathrm{H}}-C_{\mathrm{L}}<F_{\mathrm{s}}+R_{\mathrm{e}}$ and $C_{\mathrm{g}}-F_{\mathrm{g}}<R_{\mathrm{g}}<C_{\mathrm{g}}$ & 4.8 & 4.2 & 0.36 & 0.5 & 0.3 & 0.4 & 0.6 & Figure 2 \\
Case 4 & $R_{\mathrm{e}}>C_{\mathrm{H}}-C_{\mathrm{L}}$ and $R_{\mathrm{g}}<C_{\mathrm{g}}$ & 4.8 & 4.2 & 0.72 & 0.5 & 0.3 & 0.4 & 0.6 & Figure 3 \\
& $F_{\mathrm{s}}+R_{\mathrm{e}}<C_{\mathrm{H}}-C_{\mathrm{L}}$ and $C_{\mathrm{g}}-F_{\mathrm{g}}<R_{\mathrm{g}}<C_{\mathrm{g}}$ & 4.8 & 4.2 & 0.36 & 0.1 & 0.3 & 0.4 & 0.6 & Figure 4(a) \\
Case 5 & $F_{\mathrm{s}}+R_{\mathrm{e}}<C_{\mathrm{H}}-C_{\mathrm{L}}$ and $R_{\mathrm{g}}>C_{\mathrm{g}}$ & 4.8 & 4.2 & 0.36 & 0.1 & 0.3 & 0.6 & 0.4 & Figure 4(b) \\
& $R_{\mathrm{e}}>C_{\mathrm{H}}-C_{\mathrm{L}}$ and $R_{\mathrm{g}}>C_{\mathrm{g}}$ & 4.8 & 4.2 & 0.72 & 0.1 & 0.3 & 0.6 & 0.4 & Figure 5(a) \\
& $R_{\mathrm{e}}<C_{\mathrm{H}}-C_{\mathrm{L}}<F_{\mathrm{s}}+R_{\mathrm{e}}$ and $R_{\mathrm{g}}>C_{\mathrm{g}}$ & 4.8 & 4.2 & 0.36 & 0.5 & 0.3 & 0.6 & 0.4 & Figure 5(b) \\
\hline
\end{tabular}

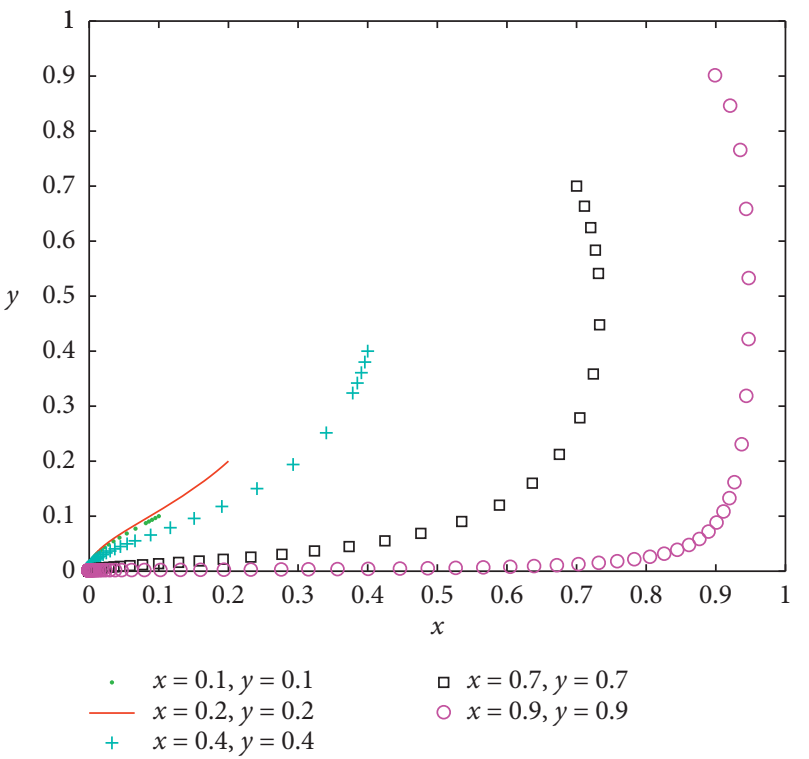

(a)

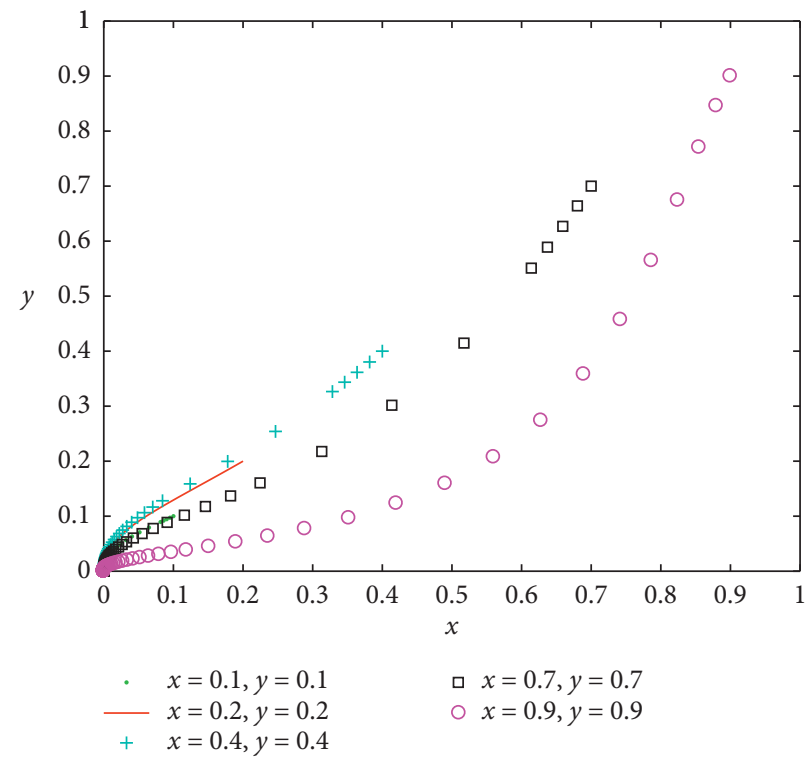

(b)

FIGURE 1: Simulation results of case 1.

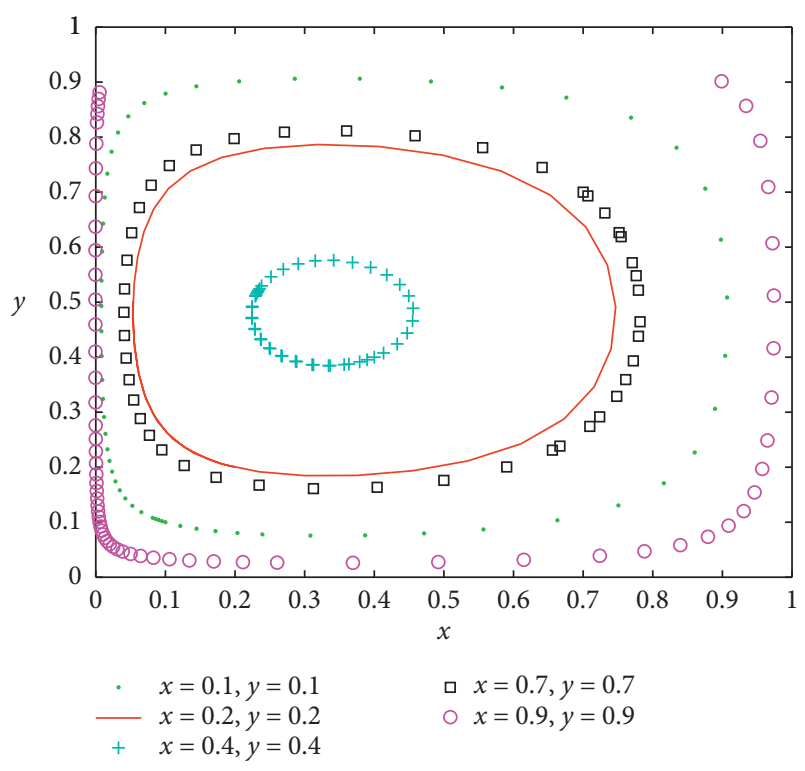

FIGURE 2: Simulation results of case 2.

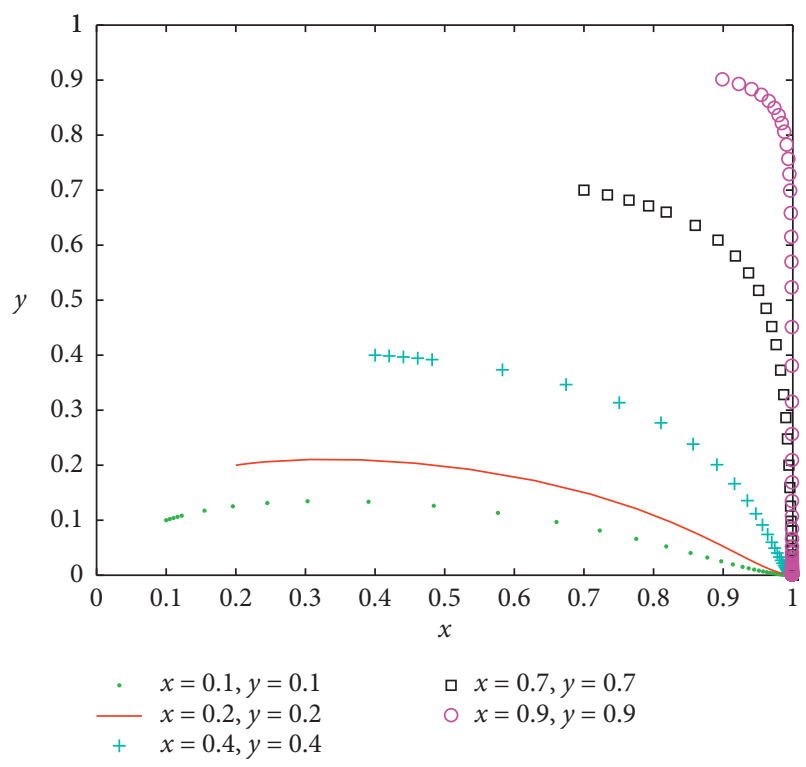

FIGURE 3: Simulation results of case 3. 


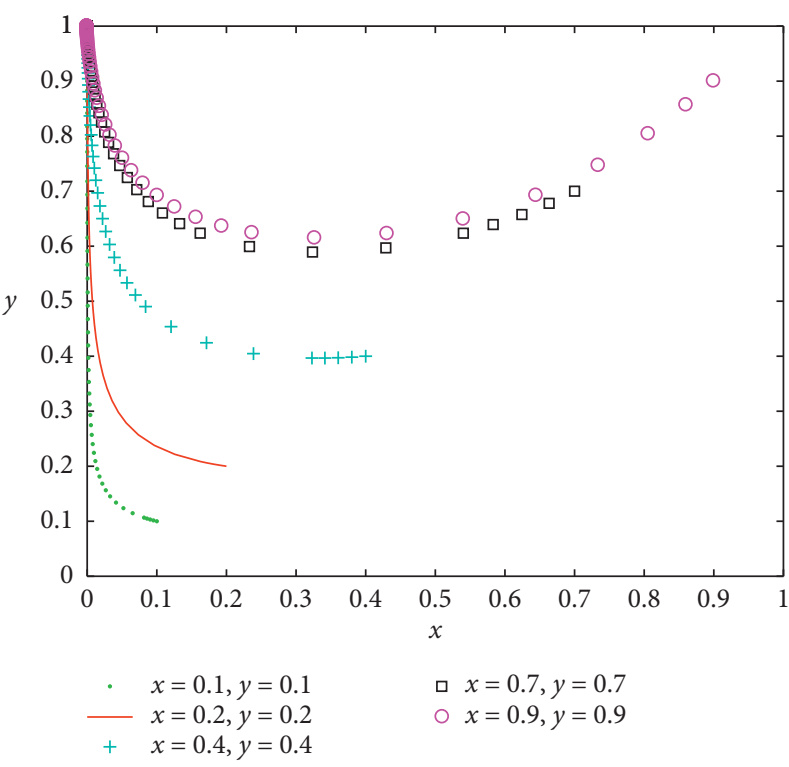

(a)

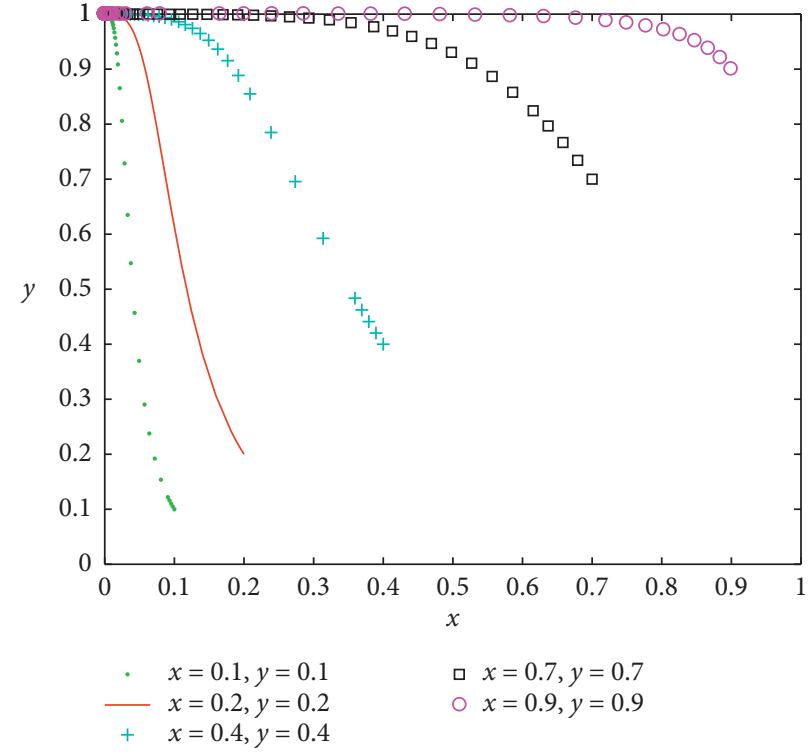

(b)

FIgURE 4: Simulation results of case 4.

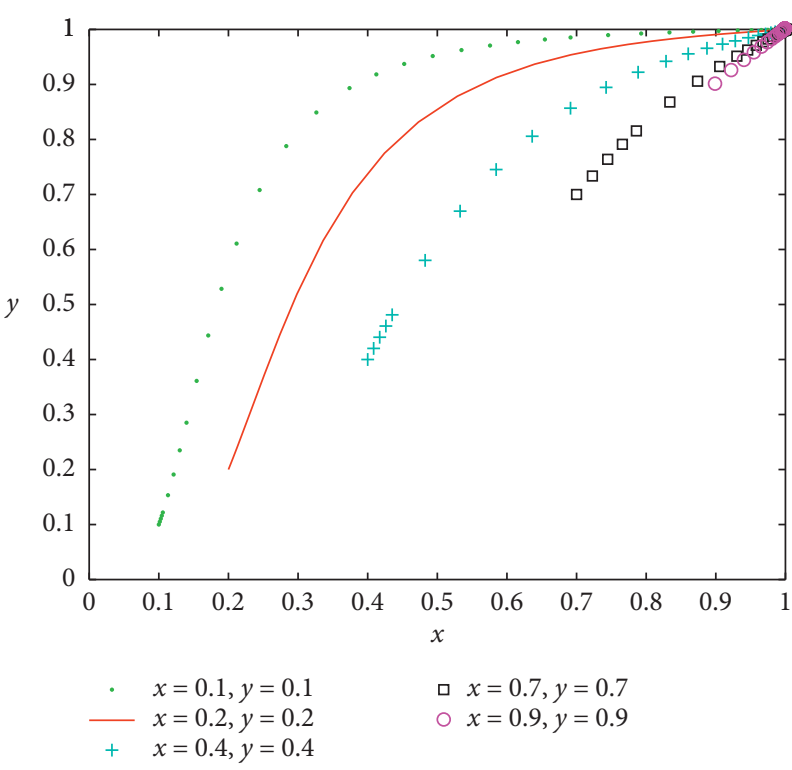

(a)

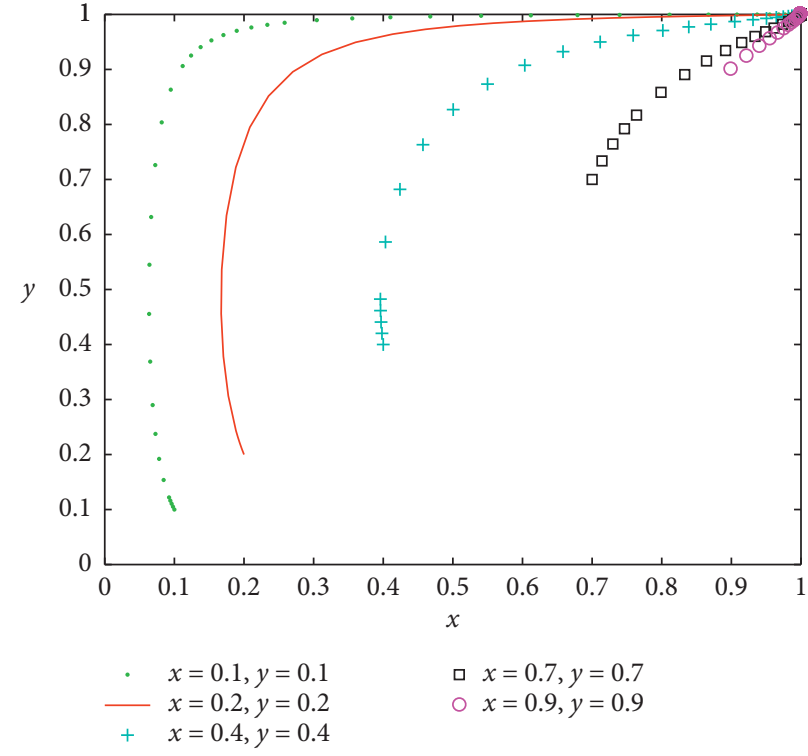

(b)

Figure 5: Simulation results of case 5.

projects becoming a"cash-for-money"approach for some people, including private investors and government officials.

(4) Figure 4 shows that the system only has one unique stable point $(0,1)$. That is to say, when the sum of the losses due to the government's punishment for private investors' illegal services and the operating subsidy obtained by the provision of high-quality services are less than the cost of providing services with low quality and when the profits gained by the active regulation of government regulators are higher than the difference between the regulatory costs and the cost of punishment for the dereliction of duty and are lower than the regulatory costs, or when the profits gained by regulation of government regulators are higher than the regulatory costs, the system will eventually evolve into a negative "locked" state in which private investors adopt LQ strategy and government regulators choose the strategy of AS. The interaction between the two sides evolved to the next worst equilibrium point. At this time, although the government regulators actively supervise, it can only curb private investors' irregularities in the short term and cannot fundamentally promote 


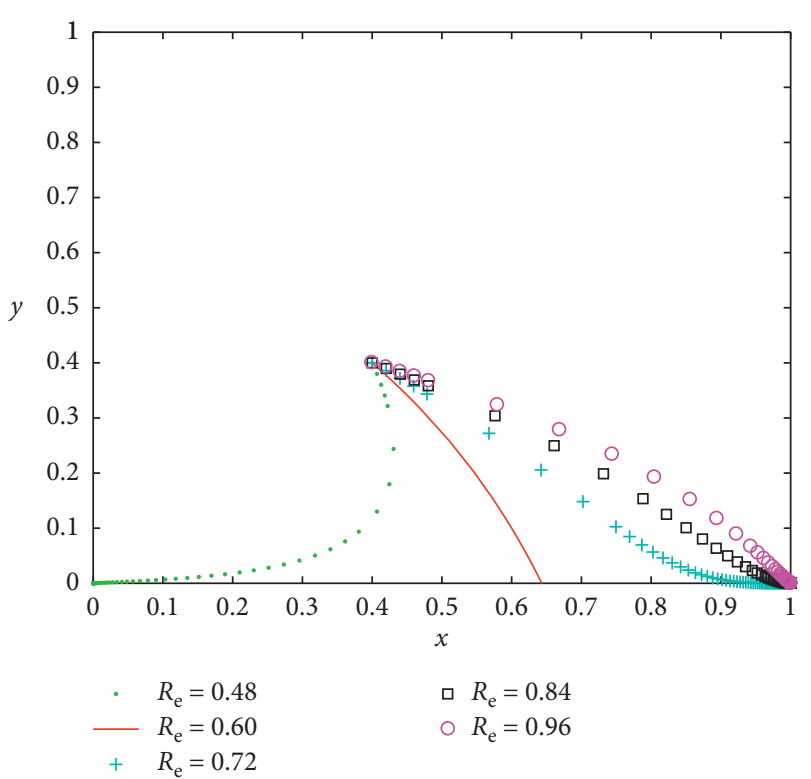

Figure 6: When $R_{\mathrm{g}}<C_{\mathrm{g}}$, evolution track with the change of $R_{\mathrm{e}}$.

private investors to improve the quality of pension services, thus affecting the high-quality development of pension PPP projects.

(5) Figure 5 shows that the system only has one unique stable point $(1,1)$. That is to say, when the cost saved by private investors through LQ is less than the sum of the losses due to the government's punishment for the private investor's illegal services and the operating subsidy obtained by the provision of highquality services and when the profits gained by the active regulation of government regulators are higher than the regulatory costs, the system will eventually evolve into an "ideal" state in which private investors adopt HQ strategy and government regulators choose the strategy of AS. This shows that the "operating subsidy" mechanism and the "punishment mechanism" for private investors are effective. The interaction between the two sides evolves into a benign equilibrium point. At this time, the government's regulatory mechanism has reached an "ideal" state. Private investors and government regulators are highly motivated. The quality of the old-age service is consciously controlled, the regulatory resources are fully utilized, the social benefits are maximized, and pension PPP projects can achieve sustainable and high-quality development.

4.2. Simulation Analysis of the Influence of Key Parameter Variables. It is assumed that both of the initial values of $x$ and $y$ are 0.4 . First, on the basis of the parameter values in case 1, i.e., the parameter assignment in Figure $1(\mathrm{a}), R_{\mathrm{e}}, F_{\mathrm{s}}$, $F_{\mathrm{g}}, R_{\mathrm{g}}$, and $C_{\mathrm{g}}$ are assumed as five sets of variables, and Matlab simulation is performed then. The results are shown in Figures 6-10. Second, on the basis of the parameter values in case 3 , i.e., the parameter assignment in Figure $3, F_{\mathrm{g}}$ is

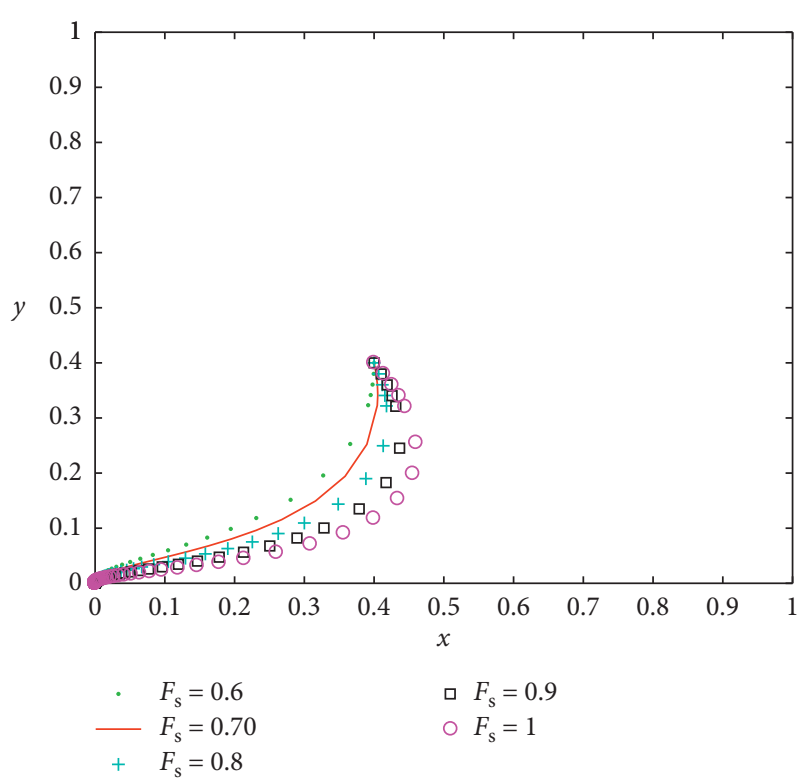

Figure 7: When $R_{\mathrm{g}}<C_{\mathrm{g}}$, evolution track with the change of $F_{\mathrm{s}}$.

assumed as a variable, and Matlab simulation is performed then. The results are shown in Figure 11. At last, based on the original value of case 4 , i.e., the parameter assignment in Figure 4(b), it is assumed that $F_{\mathrm{s}}$ or $R_{\mathrm{e}}$ should be the variable, respectively, and Matlab simulation is performed then. The results are shown in Figures 12 and 13.

(1) Figure 6 shows that, when $R_{\mathrm{e}}>0.6$, the system starts to evolve positively from the point $(0,0)$ to the point $(1,0)$. Figure 12 shows that, when $R_{\mathrm{e}}>0.48$, the system starts to evolve positively from the point $(0,1)$ to the point $(1,1)$. These results indicate that increasing operating subsidy can effectively motivate private investors to improve service quality, regardless of whether government regulators choose the strategy of AS or the strategy of NS and also show that "operating subsidy" is the key factor affecting the strategic change of private investors. Therefore, in order to motivate private investors to maintain the enthusiasm of providing high-quality services, the government can appropriately increase the operating subsidy, but when the operating subsidy is not as good as possible, the more the government will increase the financial burden and may lead to private investors' "fraudulent subsidy," which occur from time to time in China.

(2) Figure 7 shows that the increase of $F_{s}$ does not promote the benign transformation of the game system, and it is still at stable point $(0,0)$. Figure 13 shows that, when $F_{s}>0.2$, the system starts to evolve positively from the point $(0,1)$ to the point $(1,1)$. These results indicate that "punishment" is not the key factor affecting the strategic change of private investors. Under the NS strategy of government regulators, increasing punishment for private investors' violations will not change their strategy from LQ to HQ; while under the AS strategy of 


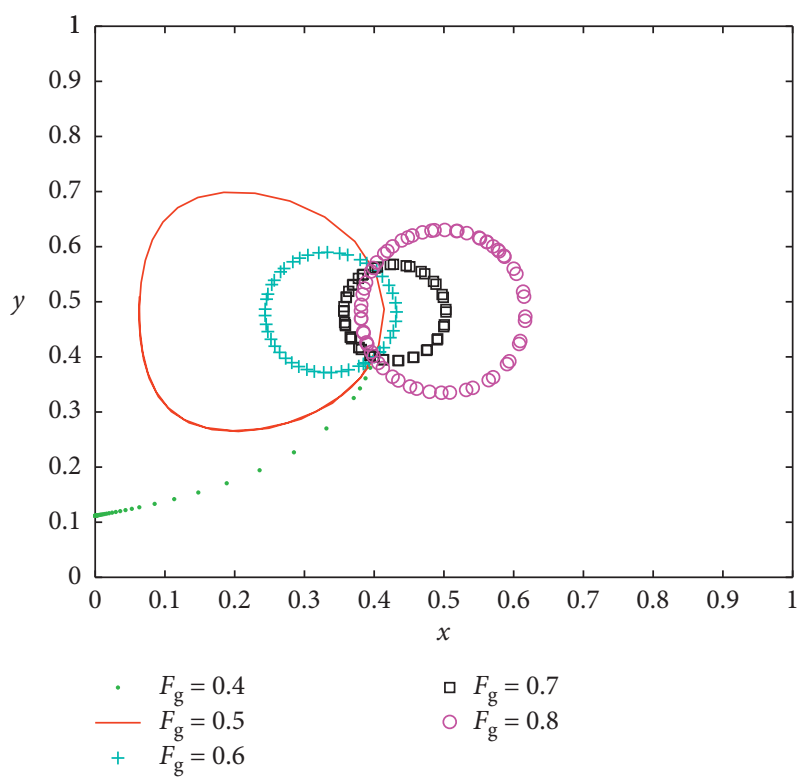

Figure 8: When $R_{\mathrm{g}}<C_{\mathrm{g}}$, evolution track with the change of $F_{\mathrm{g}}$.

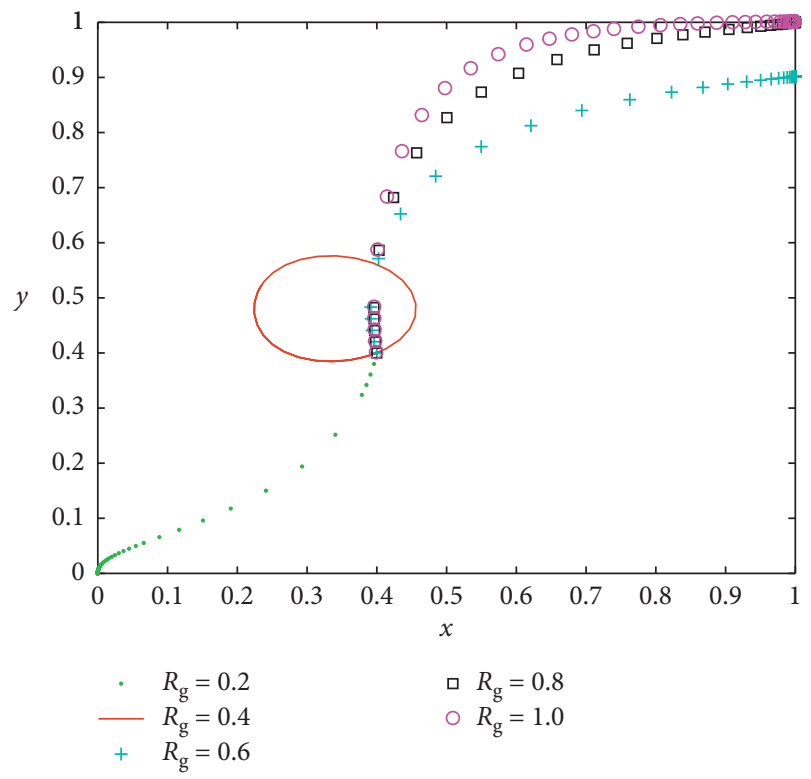

Figure 9: When $R_{\mathrm{g}}<C_{\mathrm{g}}$, evolution track with the change of $R_{\mathrm{g}}$.

government regulators, increasing punishment can restrain private investors from violating rules. However, the punishment is not as big as possible. In theory, once private investors participate in pension PPP projects, they will not easily withdraw from the ones. In practice, if the punishment is excessive, beyond the scope of the private investors can bear, it is very likely that private investors will "flee" from the projects, thus leading to the failure of the pension PPP projects. Therefore, the Chinese government should choose appropriate punishment to encourage private investors to provide high-quality services without leading them to withdraw from projects.

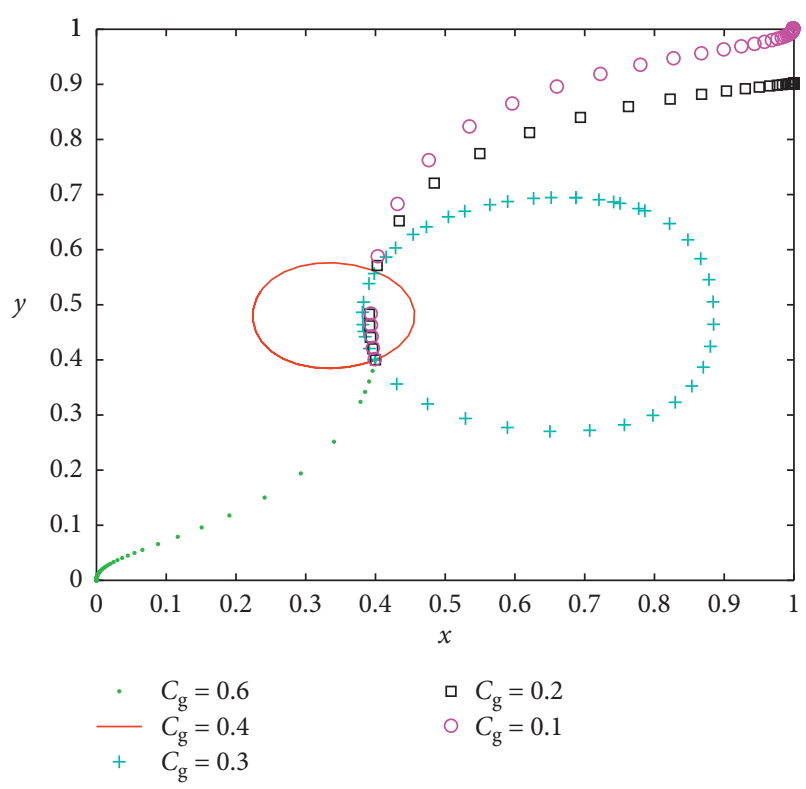

Figure 10: When $R_{\mathrm{g}}<C_{\mathrm{g}}$ evolution track with the change of $C_{\mathrm{g}}$.

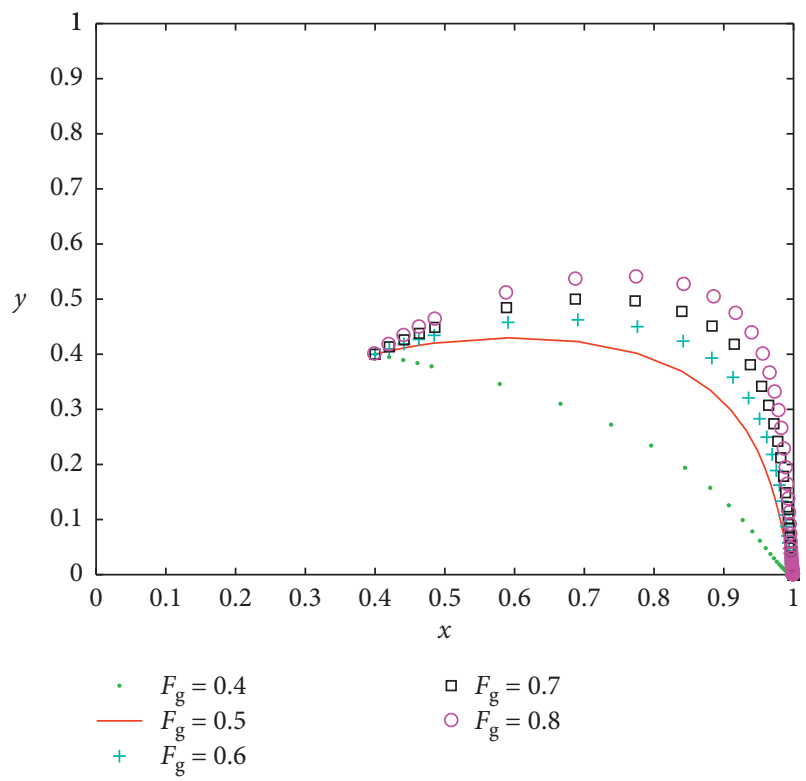

FIgURE 11: When $R_{\mathrm{g}}<C_{\mathrm{g}}$, evolution track with the change of $F_{\mathrm{g}}$.

(3) Figure 8 shows that with the increase of punishment from superiors to government regulators. The system evolves from a stable state point $(0,0)$ to an unstable state, similar to the state in Case 2. Figure 11 shows that the system is still at a stable point $(1,0)$ with the increase of punishment imposed on government regulators. These indicate that when $R_{\mathrm{g}}<C_{\mathrm{g}}$, increasing the punishment for dereliction of duty by the supervisor cannot fundamentally change the supervisory strategy of government regulators. At the same time, these also show that punishment from the superiors is not a key factor affecting the choice of regulatory behavior strategies of government regulators. Therefore, in the case of the NS strategy 


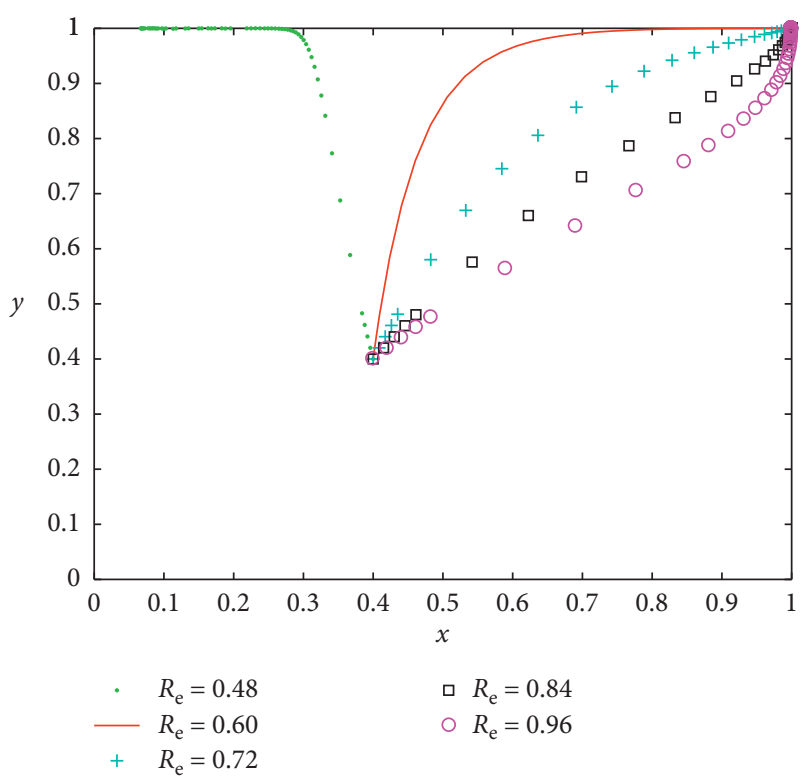

Figure 12: When $R_{\mathrm{g}}>C_{\mathrm{g}}$, evolution track with the change of $R_{\mathrm{e}}$.

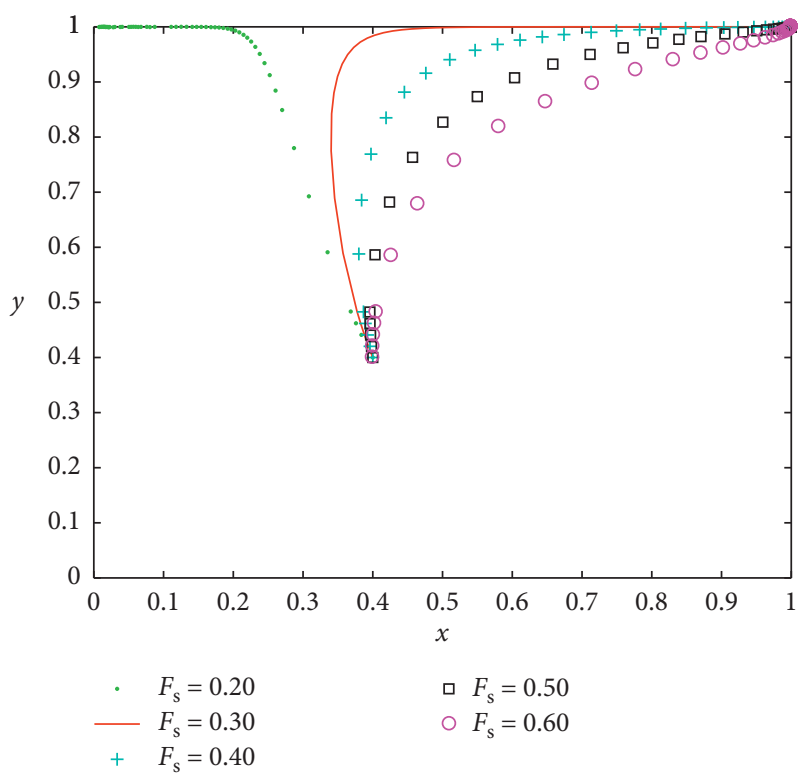

Figure 13: When $R_{\mathrm{g}}>C_{\mathrm{g}}$, evolution track with the change of $F_{\mathrm{s}}$.

chosen by government regulators, even if the higher government increases the punishment for the government regulators' negligence, it cannot fundamentally change the supervision strategy of government regulators.

(4) Figure 9 shows that as the supervision benefit of government regulators increases continually, the system first evolves from the stable state $(0,0)$ to an unstable state. Finally, when $R_{\mathrm{g}}>0.6$, the system eventually tends to be the stable state of $(1,1)$. Figure 10 shows that as the supervision cost of government regulators reduces continually, when $C_{\mathrm{g}}<0.6$, the system eventually tends to be the stable state of $(1,1)$.These indicate that, when the supervision benefit is greater than the supervision cost, government regulators will choose the strategy of AS, and private investors will adopt HQ strategy. At the same time, these also show that supervision benefit and supervision cost are the key factors affecting the choice of regulatory behavior strategies of government regulators. Thus, increasing government supervision benefit or reducing government supervision cost can effectively improve the supervision enthusiasm of government regulators, so as to promote private investors to improve the pension service quality under the strategy of AS by government regulators.

\section{Main Conclusions and Suggestions}

5.1. Main Conclusions. Aiming at solving problems of service quality supervision in China's pension PPP projects, this paper constructs the evolutionary game model between private investors and government regulators. From the stability analysis of evolution strategies of both sides and the results of Matlab simulation, it can be concluded that "operating subsidy" is the key factor affecting private investors' strategic choice, and improving operating subsidy can effectively motivate private investors to improve service quality. "Punishment" is neither the key factor affecting the choice of private investors' strategies nor the key factor affecting the regulatory strategies of government regulators. Under the active supervision of government regulators, increasing punishment can restrain private investors from violating rules. If government regulators fail to perform their duties, however, punishment will be ineffective to private investors who have broken the rules. "Supervision benefit" and "supervision cost" are the key factors affecting the choice of regulatory behavior strategies of government regulators. Increasing the supervision benefit of government regulators or reducing the supervision cost can improve the sense of responsibility of government regulators, so as to promote private investors to improve the pension service quality. Therefore, the Chinese government should take appropriate measures to improve the sense of responsibility of government regulators who appropriately punish private investors providing low-quality services and appropriately increase operating subsidies to private investors offering high-quality services.

5.2. Suggestions for the Government. In order to improve the effectiveness of the government's supervision on the service quality of pension PPP, the following specific measures are put forward.

Firstly, the government should optimize the supervision mechanism, strengthen supervision, and highlight the effectiveness of "operating subsidy" and "punishment". Operating subsidies should be increased appropriately for private investors who provide high-quality services. Appropriate punishment measures should be taken for private investors' breach of contract, so as to ensure that they not 
only provide high-quality services but also do not withdraw from the projects. Secondly, a unified and efficient service center for pension PPP projects and an information system for quality supervision and management of pension PPP projects should be established, which intelligently supervises with the help of big data technology, so as to reduce the cost in the process of supervision. At the same time, the supervision benefit of local government regulators should be increased. Finally, the government should introduce other mechanisms, such as "public participation", "third-party evaluation," and "reputation incentives" to prevent the punishment mechanism from failing under the negative supervision case of government regulators.

5.3. Author's Prospect. The supervision of PPP service quality for the aged is a game process involving multistakeholders. In this study, only two game players of private investors and government regulators are considered. In the follow-up study, the third-party evaluation institutions and consumers are included in the game subject. The game model will also consider more factors, such as "public participation" and "reputation incentive" as variables in the model, and explore the internal mechanism of the multidimensional supervision model of PPP service quality for the aged.

\section{Data Availability}

The data used to support the findings of this study are included within the article.

\section{Conflicts of Interest}

The authors declare no conflicts of interest.

\section{Acknowledgments}

This research was supported by the Major Project of Key Research Base of the Ministry of Education of China under Grant no. 16JJD840011 and National Social Science Foundation Later-Stage Funding Project of China under Grant no. 18FGL026.

\section{References}

[1] L. Gao and Z. Zhao, "System dynamics analysis of evolutionary game strategies between the government and investors based on new energy power construction public-private-partnership (PPP) project," Sustainability, vol. 10, no. 7, 2533 pages, 2018.

[2] S. P. Ho, "Model for financial renegotiation in public-private partnership projects and its policy implications: game theoretic view," Journal of Construction Engineering and Management, vol. 132, no. 7, pp. 678-688, 2006.

[3] J.-E. de Bettignies, J. E., and T. W. Ross, "Public-private partnerships and the privatization of financing: an incomplete contracts approach," International Journal of Industrial Organization, vol. 27, no. 3, pp. 358-368, 2009.

[4] P. Xiang, X. Huo, and L. Shen, "Research on the phenomenon of asymmetric information in construction projects-the case of China," International Journal of Project Management, vol. 33, no. 3, pp. 589-598, 2015.
[5] J. Liu, R. Gao, C. Y. J. Cheah, and J. Luo, "Evolutionary game of investors' opportunistic behaviour during the operational period in PPP projects," Construction management and economics, vol. 35, no. 3, pp. 137-153, 2017.

[6] X. Chao and S. Mao, "Cooperative advantage, operational mode and regulation design: analysis of PPP model of institutional pension in F province," Theoretical Investigation, no. 3, pp. 171-176, 2017, in Chinese.

[7] M. I. Sabry, "Good governance, institutions and performance of public private partnerships," International Journal of Public Sector Management, vol. 28, no. 7, pp. 566-582, 2015.

[8] S. Zhang, Y. Gao, Z. Feng, and W. Sun, "PPP application in Infrastructure development in China: institutional Analysis and implications," International Journal of Project Management, vol. 33, no. 3, pp. 497-509, 2015.

[9] B. Li, A. Akintoye, P. J. Edwards, and C. Hardcastle, "Critical success factors for PPP/PFI projects in the UK construction industry," Construction Management and Economics, vol. 23, no. 5, pp. 459-471, 2005.

[10] L. Qiao, S. Q. Wang, R. L. K. Tiong, and T.-S. Chan, "Framework for critical success factors of BOT projects in China," The Journal of Structured Finance, vol. 7, no. 1, pp. 53-61, 2001.

[11] X. Liu and K. Zhang, "A research on the supervision mechanism for private and public partnership providing public goods," Economic Survey, vol. 6, pp. 19-22, 2008, in Chinese.

[12] H. Chen, W. Wang, and D. Guo, "Government and social capital Cooperating (PPP): rent-seeking game and regulation strategies," Public Finance Research, no. 10, pp. 20-24, 2014, in Chinese.

[13] Q. Zhou and C. Liu, "On the introduction of public-private partnership mechanism in China's public service," Journal of Shanxi University of Finance and Economics, vol. 34, no. 5, 6 pages, 2012, in Chinese.

[14] P. R. Cohen and H. J. Levesque, "Intention is choice with commitment," Artificial Intelligence, vol. 42, no. 2, pp. 213261, 1990.

[15] O. Morgenstern and N. J. Von, Theory of Games and Economic Behavior, Princeton University Press, Princeton, NJ, USA, 1953.

[16] M. Wooldridge and N. R. Jennings, "The cooperative problem-solving process," Journal of Logic and Computation, vol. 9, no. 4, pp. 563-592, 1999.

[17] J. Nash, "Non-cooperative games," Ph.D. thesis, Mathematics Department, Princeton University, Princeton, NJ, USA, 1950.

[18] J. W. Weibull, "The mass-action interpretation of nash equilibrium," IUI Working Paper, No. 427, The Research Institute of Industrial Economics (IUI), Stockholm, Sweden, 1994, http://hdl.handle.net/10419/95056.

[19] S. Zhang, C. Wang, and C. Yu, "The evolutionary game analysis and simulation with system dynamics of manufacturer's emissions abatement behavior under cap-and-trade regulation," Applied Mathematics and Computation, vol. 355, pp. 343-355, 2019.

[20] F. Fu, D. I. Rosenbloom, L. Wang, and M. A. Nowak, "Imitation dynamics of vaccination behavior on social networks," Proceedings of the Royal Society B: biological Sciences, vol. 278, no. 1702, pp. 42-49, 2010.

[21] Y. e. Wu, B. Zhang, and S. Zhang, "Probabilistic reward or punishment promotes cooperation in evolutionary games," Chaos, Solitons \& Fractals, vol. 103, pp. 289-293, 2017.

[22] K. Jiang, D. You, R., and Z. Li, "Implementation of a multiagent environmental regulation strategy under Chinese fiscal decentralization: an evolutionary game theoretical 
approach," Journal of Cleaner Production, vol. 214, pp. 902-915, 2019.

[23] P. Merrill, Y. He, and F. Xu, "Evolutionary analysis of sustainable tourism," Annals of Tourism Research, vol. 69, pp. 76-89, 2018.

[24] Q. Liu, X. Li, and X. Meng, "Effectiveness research on the multi-player evolutionary game of coal-mine safety regulation in China based on system dynamics," Safety Science, vol. 111, pp. 224-233, 2019.

[25] J. Tanimoto, "Evolutionary games with sociophysics: analysis of traffic flow and epidemics," vol. 17, Springer, Berlin, Germany, 2018.

[26] B. Guo and J. Li, "Research on the evolution of participants collaboration mechanism in PPP model based on computer simulation: based on the old community renovation project," The Journal of Supercomputing, no. 9, pp. 1-18, 2018.

[27] N. Li and C. Ma, "Evolutionary game analysis on supervision of PPP project tender," in Proceedings of the 2018 7th International Conference on Industrial Technology and Management (ICITM), IEEE, pp. 190-193, Oxford, UK, March 2018.

[28] L. Gao and Z.-Y. Zhao, "System dynamics analysis of evolutionary game strategies between the government and investors based on new energy power construction publicprivate-partnership (PPP) project," Sustainability, vol. 10, no. 7, p. 2533, 2018.

[29] C. Li, X. Li, and Y. Wang, "Evolutionary game analysis of the supervision behavior for public-private partnership projects with public participation," Mathematical Problems in Engineering, vol. 2016, p. 8, 2016.

[30] G. Wang, Y. Xue, M. Skibniewski et al., "Analysis of private investors conduct strategies by governments supervising public-private partnership projects in the new media era," Sustainability, vol. 10, no. 12, 4723 pages, 2018.

[31] J. W. Weibull, Evolutionary game theory, Vol. 78, Massachusetts Institute of technology, Cambridge, MA, USA, 1995.

[32] D. Friedman, "Evolutionary games in economics," Econometrica, vol. 59, no. 3, pp. 637-666, 1991. 


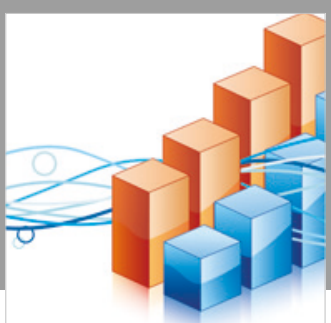

Advances in

Operations Research

\section{-n-m}
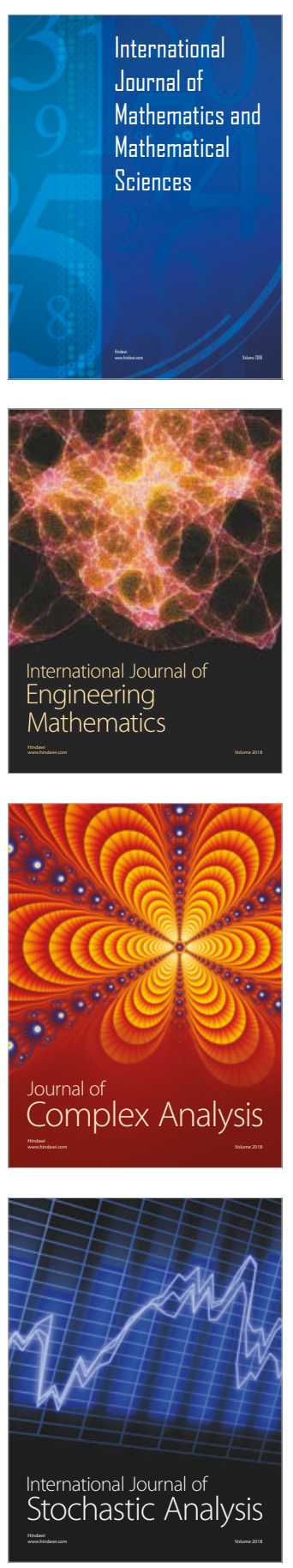
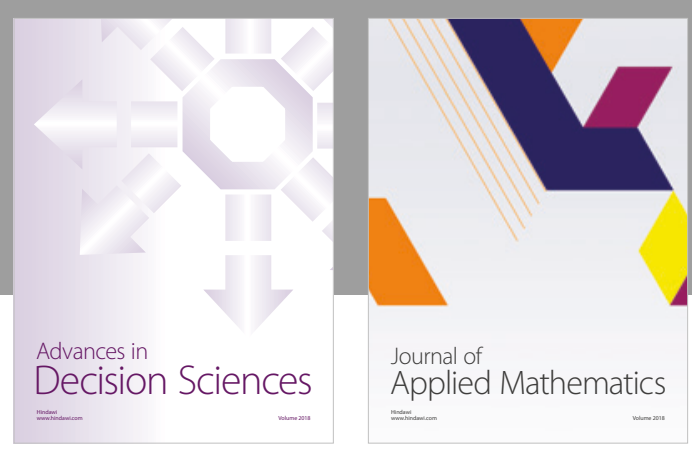

Journal of

Applied Mathematics
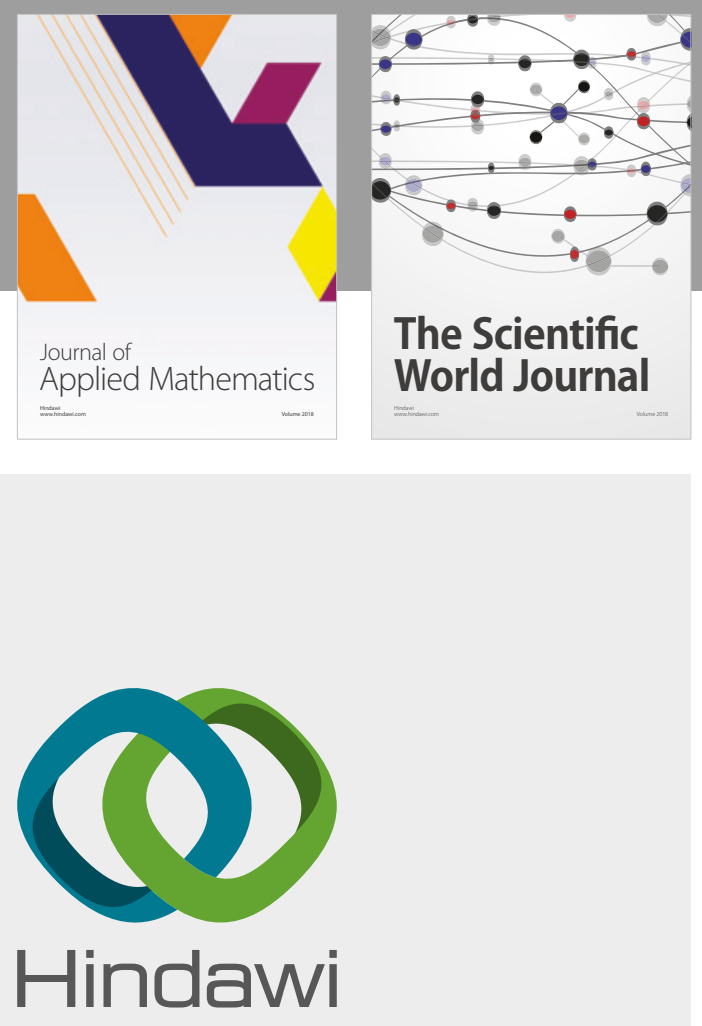

Submit your manuscripts at

www.hindawi.com

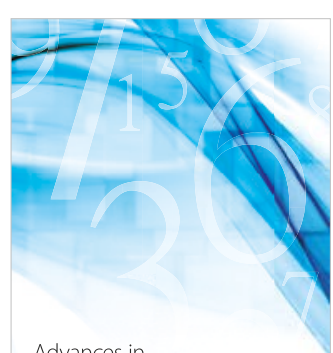

Advances in
Numerical Analysis
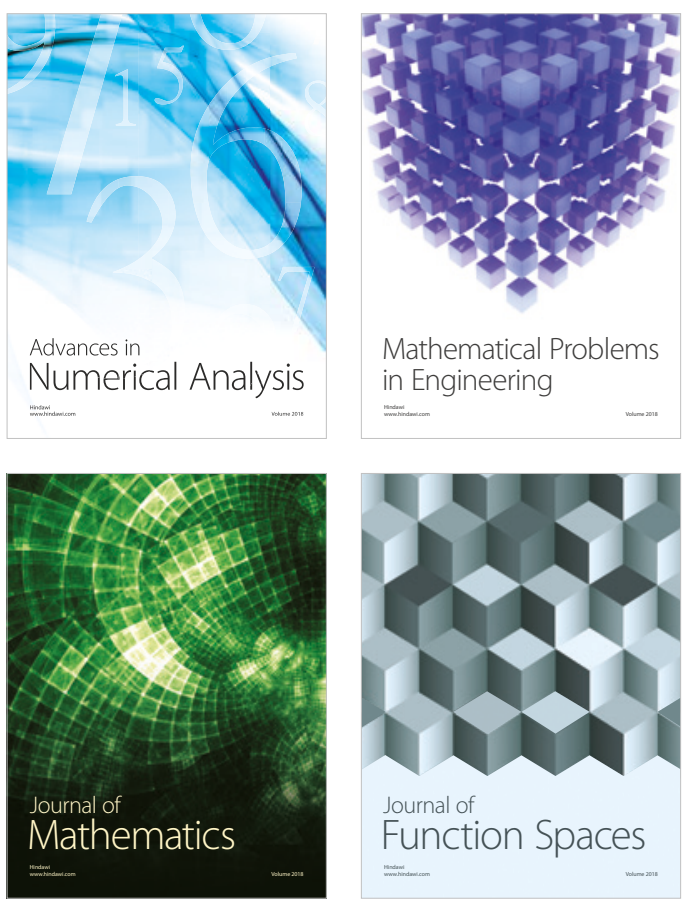

Mathematical Problems in Engineering

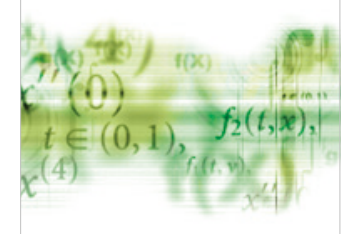

International Journal of

Differential Equations

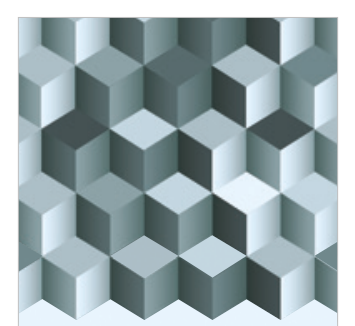

Journal of

Function Spaces

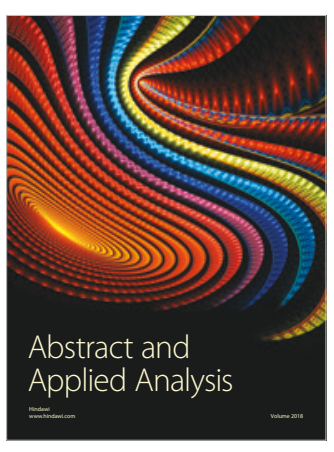

The Scientific

World Journal

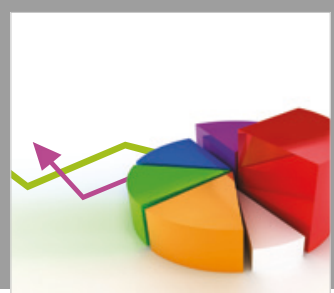

Journal of

Probability and Statistics
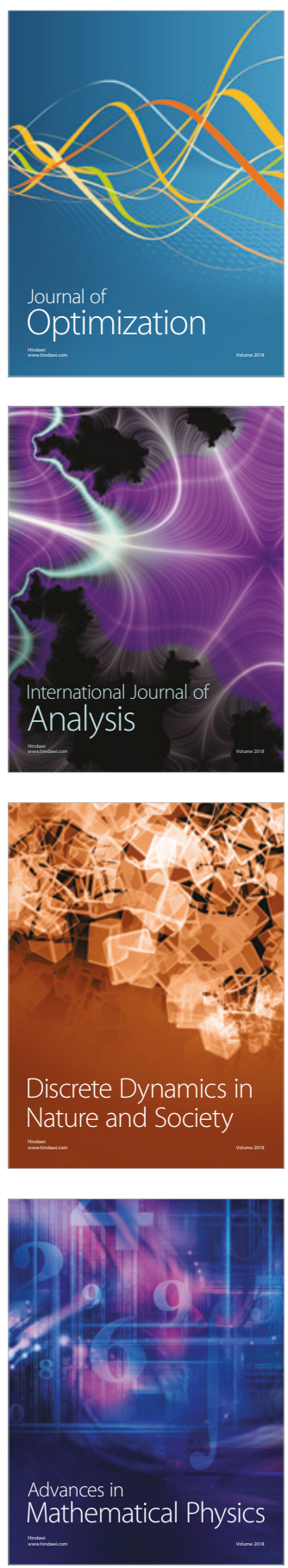